\title{
Philipp Batthyány
}

\section{Zwang als Grundübel in der Gesellschaft?}

\author{
Der Begriff des Zwangs bei Friedrich August von Hayek
}

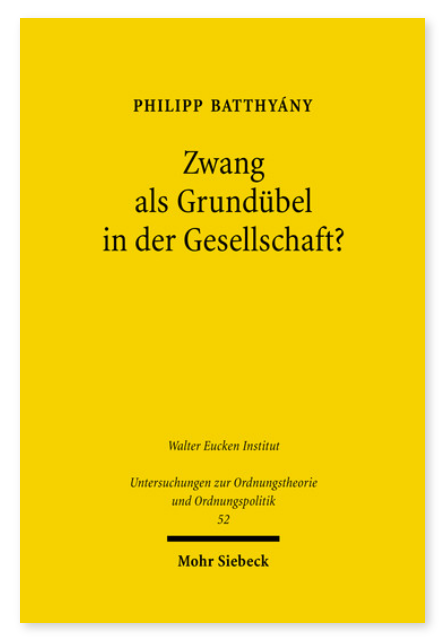

2007. XII, 242 Seiten. UOrd 52

ISBN 978-3-16-151477-7

DOI 10.1628/978-3-16-151477-7

eBook PDF $64,00 €$

ISBN 978-3-16-149365-2

fadengeheftete Broschur 64,00€
Grundbegriff des klassischen Liberalismus ist der Begriff der negativen Freiheit: Freiheit als Abwesenheit von Zwang. Doch was ist Zwang? Warum ist Zwang in der freiheitlichen Sicht ein Übel? Der liberale Nationalökonom und Sozialphilosoph Friedrich August von Hayek entwickelt in seiner Verfassung der Freiheit eine Bestimmung des Begriffspaars Freiheit und Zwang, die jedoch unvollständig bleibt und einige grundsätzliche Fragen an seine Moralphilosophie und Theorie der kulturellen Evolution aufwirft. Philipp Batthyány unternimmt den Versuch einer werkimmanenten Definition des Zwangsbegriffs Hayeks und einer Begründung für die Verwerflichkeit des Zwangs als Grundübel in der Gesellschaft. Unter Einbeziehung wesentlicher Teile des unveröffentlichten Nachlasses durchdringt der Autor Hayeks Gesamtwerk mit Blick auf die ihm zugrundeliegende Konzeption von Freiheit und Zwang und schließt damit eine wichtige Lücke in der Hayek-Forschung.

Philipp Batthyány Geboren 1968 in Genf; Studium der Philosophie an der Jesuitenuniversität Hochschule für Philosophie S.J., München; 2006 Promotion; 2018 Habilitation; Professor für Sozial- und Moralphilosophie an der Internationalen Akademie für Philosophie des Fürstentums Liechtenstein, IAP.

Jetzt bestellen:

https://mohrsiebeck.com/buch/zwang-als-grunduebel-in-der-gesellschaft-9783161514777?no_cache=1 order@mohrsiebeck.com

Telefon: +49 (0)7071-923-17

Telefax: +49 (0)7071-51104 